\title{
Episiotomy: Epidemiological Aspects, Indications and Prognosis in the Bogodogo Health District
}

\author{
Ouattara Adama ${ }^{1,2 *}$, Lankoandé Bako Natacha ${ }^{3}$, Ouédraogo Smaila ${ }^{1,2}$, Sawadogo Yobi Alexis ${ }^{1,2}$, \\ Millogo Traoré Francoise ${ }^{1,2}$, Ouédraogo Marie Charlemagne ${ }^{1,2}$, Ouédraogo Ali ${ }^{1,2}$, \\ Thieba Bonané Blandine ${ }^{1,2}$
}

\begin{abstract}
${ }^{1}$ Training and Research Unit in Health Sciences (TRU/HS), University Ouaga 1 Pr Joseph KI ZERBO, Ouagadougou, Burkina Faso ${ }^{2}$ Department of Gynecology and Obstetrics, The University Teaching Hospital Yalgado Ouedraogo of Ouagadougou (UTH-YO), Ouagadougou, Burkina Faso

${ }^{3}$ Department of Gynecology and Obstetrics, The Bogodogo University Teaching Hospital of Ouagadougou (UTH-B), Ouagadougou, Burkina Faso

Email: *ouattzangaadama@yahoo.fr
\end{abstract}

How to cite this paper: Adama, O., Natacha, L.B., Smaila, O., Alexis, S.Y., Francoise, M.T., Charlemagne, O.M., Ali, O. and Blandine, T.B. (2018) Episiotomy: Epidemiological Aspects, Indications and Prognosis in the Bogodogo Health District. Open Journal of Obstetrics and Gynecolo$g y, 8,1354-1363$.

https://doi.org/10.4236/ojog.2018.813137

Received: October 7, 2018

Accepted: November 9, 2018

Published: November 12, 2018

Copyright (c) 2018 by authors and Scientific Research Publishing Inc. This work is licensed under the Creative Commons Attribution International License (CC BY 4.0).

http://creativecommons.org/licenses/by/4.0/

\begin{abstract}
Objectives: To study the epidemiological aspects, indications and short and medium term prognosis of episiotomy in the health district of Bogodogo in Ouagadougou, Burkina Faso. Materials and Method: It was a descriptive prospective study over 4 months from 1 July 2016 to 30 October 2016. It was conducted in 4 health facilities in the health district of Bogodogo in the city of Ouagadougou. The study concerned the patients who gave birth after 28 gestational age (GA) and more, vaginally with episiotomy, in the 4 health facilities and who were reviewed at the appointment of the 9th day and the 3rd month. The data were collected using a questionnaire developed for the purposes of the study, seized with a laptop, then analyzed using the Epi-info software in its 3.5.1 version of the Atlanta C.D.C. Statistical comparisons were made using the Pearson chi-square test, with a significance level of $\mathrm{p}<0.05$. Results: The overall episiotomy rate was $22 \%$. For follow-up, 248 patients were reviewed on the 9th day and 109 patients on the $3 \mathrm{rd}$ month. The average age of our patients was 23.1 years. The average number of pregnancies was 1.7 with nulliparous women predominating (60.5\% of cases). Excision was associated with episiotomy in $92.3 \%$ of cases, with perineal narrowing in $82.5 \%$ of patients. The mediolateral episiotomy was the most performed, in $76.6 \%$ of patients. Vulvo-perineal stricture was the main indication $(75 \%$ of cases). The experience during the episiotomy and the evolution following the immediate layer was marked by pain. Dyspareunia was the main difficulty in resuming sexual intercourse. Conclusion: The episiotomy rate in our study
\end{abstract}


was $22 \%$. A program of continuous improvement of the quality of care concerning episiotomy encompassing various actions (audits, training) could reduce the use of episiotomies.

\section{Keywords}

Episiotomy, Epidemiology, Bogodogo

\section{Introduction}

The perineum is the set of soft parts that close the pelvic excavation at the bottom [1]. It consists of 3 large muscle planes (superficial, medium, deep). Introduced by Sir FIELDING OULD, in Dublin in 1742 to facilitate childbirth, episiotomy is in fact a perineotomy which is now common practice [2]. It consists of the section of a part of the perineum from the posterior corner of the vulva after distension of the perineum by the foetal pole in order to facilitate the exit of the child. It measures three to four centimeters in length on average and can be median or medio-lateral. Episiotomy aims on the one hand to avoid severe perineal tears in the short term and to prevent more long-term pelvic static disorders (genitourinary prolapse, stress urinary incontinence, anorectal lesions). On the other hand, it aims to shorten expulsion, reduce foetal trauma and facilitate obstetrical maneuvers [1]. First, episiotomy remained relatively confidential and during the 20th century became the most common obstetrical procedure performed in delivery rooms in the West outside the umbilical cord section. Traditional obstetric education saw in her an act of prevention of maternal and perinatal morbidity par excellence. The advent of evidence-based medicine at the end of the last century had a strong impact on medical practices, including episiotomy [3].

Thus, the first review of the literature on the value of a systematic episiotomy policy dates back to 1983 and the first randomized trial on the subject dates from 1984 [4] [5]. Since then, other publications have regularly highlighted the lack of interest in a systematic episiotomy policy and the risks associated with carrying out such an act [6]. In recent years, there has been a varying reduction in the use of episiotomy in many countries.

In Burkina Faso, a study on the frequency of episiotomy was already carried out in 1998 showing a very high rate of practice (32.1\%) [7]. However, since epidemiological aspects, indications and prognosis have not been studied, we propose to study these aspects in the health district of Bogodogo in Ouagadougou.

\section{Materials and Method}

The study was conducted in Ouagadougou, in the health district of Bogodogo. The health district of Bogodogo is one of the 65 health districts in the country. It forms with the health district of Baskuy, Boulmiougou, Nongremasson and Signongh in the 5 health districts of the capital. More specifically, it concerned four health facilities in this district. The health district of Bogodogo had an estimated 
population of 588,583 in 2016. This was a descriptive prospective study conducted from July 01 to October 30, 2016, a period of 04 months; the follow-up lasted until January 30, 2009. The study concerned parturient women who had given birth (after 28 weeks of amenorrhoea) vaginally with an episiotomy in the four health facilities and who were seen again on the 9th day and 3rd month. The analysis involved 248 women who gave birth vaginally with episiotomy in the study sites. Were not included in our sample the cases of fetal deaths in ute-

ro. The studied variables included:

- socio-demographic characteristics (age, origin, marital and professional status);

- risk factors (gynecological-obstetrical history, clinical status of the perineum);

- indications of episiotomy;

- the technique of realization of the episiotomy;

- the experience of the episiotomy by the woman at the time of the practice and later;

- the sexual experience of the woman;

- complications (immediate and medium term).

Data were collected using a questionnaire developed for the study. The data collected by the collection cards were analyzed using the Epi-info software in its English version 3.5.1 of the C.D.C of Atlanta. Statistical comparisons were made using the Pearson chi-square test, with a significance level of $p<0.05$. The study was approved by the ethic committee and also by patients.

\section{Results}

\subsection{Frequency of Episiotomy during the Study Period}

During the 4 months of the study we recorded 813 cases of episiotomy for 3703 vaginal deliveries, an overall rate of $22 \%$.

\subsection{Socio-Demographic Characteristics}

The average age was $23.1 \pm 5$ years with extremes of 15 and 40 years. The age distribution of patients was shown in Figure 1. The $15-19$ and $20-24$ age groups are the most affected, accounting for $38 \%$ of cases each.

The mean was 0.7 pare \pm 1 , with extremes of 0 and 5; Figure 2 shows the distribution by tench of parity. In our sample, nulliparous women are mostly represented, i.e. $60.5 \%$ of patients.

\subsection{Data at Childbirth}

The distribution of data at birth was presented in Table 1.

\subsection{Indications for Episiotomy}

The indications found are illustrated in Figure 3. Vulvo-perineal narrowing predominated in our sample in 186 patients, $75 \%$ of the indications. 


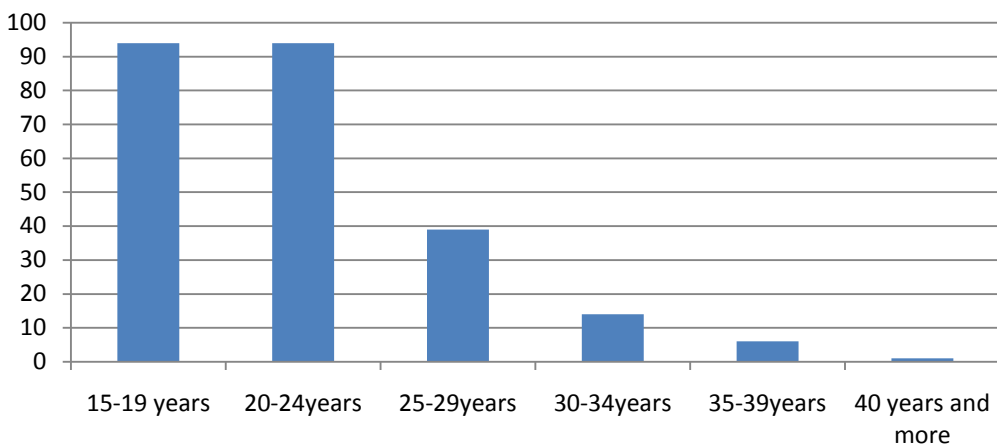

number

Figure 1. Age distribution of patients.

\section{number of anterior chilbirth}

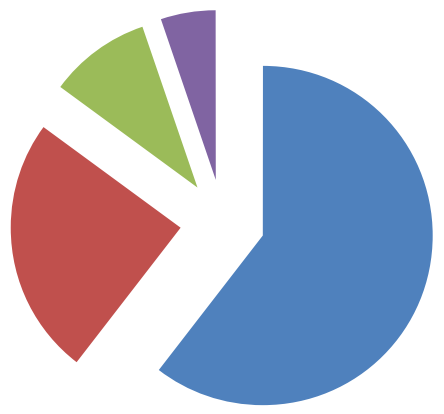

Figure 2. Anterior childbirth distribution of patients.

\section{Indications of the episiotmy}

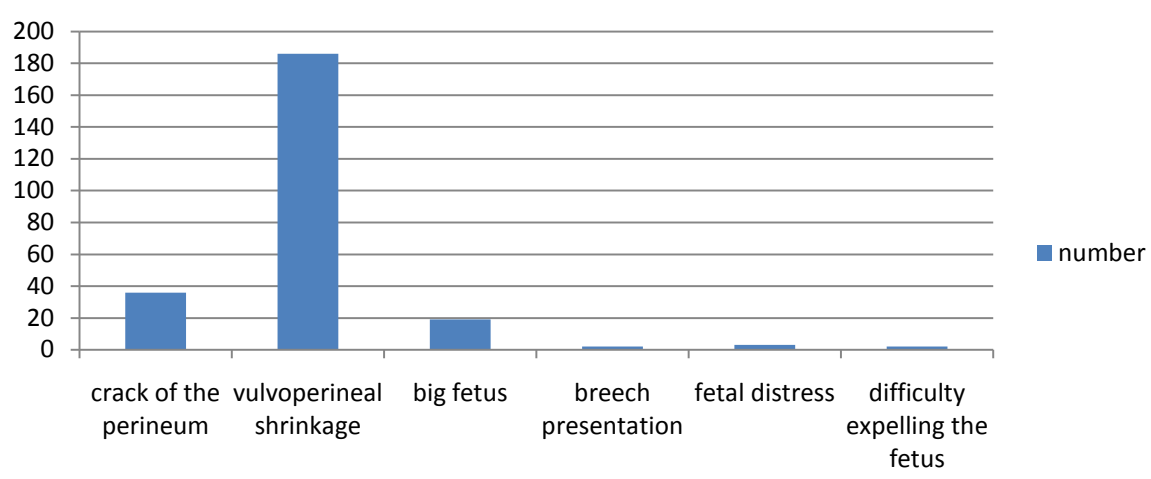

Figure 3. Distribution of patients according to episiotomy indications.

Table 1. Childbirth data.

\begin{tabular}{cccc}
\hline & Average & Standard deviation & Extremes \\
\hline Number of live children & 1 & 0.4 & $1-2$ \\
Weight of the child & $2937.6 \mathrm{~g}$ & 420.1 & $1800-4160 \mathrm{~g}$ \\
Cranial perimeter & $32.4 \mathrm{~cm}$ & 2.5 & $29-37 \mathrm{~cm}$ \\
height & $49.1 \mathrm{~cm}$ & 4.9 & $33-59 \mathrm{~cm}$ \\
Apgar score (1st minute) & 8.2 & 1.9 & $0-10$ \\
Apgar score (5th minute) & 9.4 & 1.2 & $0-10$ \\
\hline
\end{tabular}




\subsection{Type of Episiotomy}

The main types of episiotomies are reported in Table 2. The mediolateral episiotomy was the most performed with $77.5 \%$ or 190 patients.

\subsection{Prognosis}

\section{- Immediate diaper suites}

The evolution in immediate diaper suites has been summarized in Table 3.

\section{- Experience during episiotomy}

The distribution of patients according to their experience during the episiotomy was represented in Table 4.

Patient's condition on the 9th day. The evolution on the 9th day has been summarised in Table 5. One hundred and eighty-five (185) of our deliveries, or $74.6 \%$, had a simple continuation. Forty (40) women, or $16.1 \%$, had a suture release.

\section{- Condition at the 3rd month}

Only 109 patients were seen after 3 months; that is $43.95 \%$ (Figure 4):

$\checkmark$ Good healing was obtained in $98.2 \%$ of cases (107 cases);

$\checkmark 56$ patients had resumed sexual intercourse; $51.4 \%$;

$\checkmark$ The difficulties identified are mainly dyspareunia and a decrease in sexual sensitivity.

\subsection{Study of the Factors Associated with Performing an Episiotomy}

\section{- Excision and narrowing of the perineum}

The relationship between excision and perineal narrowing is shown in Table 6 .

Table 2. Distribution of patients by episiotomy type.

\begin{tabular}{ccc}
\hline Type of episiotomy & Frequency & Percentage (\%) \\
\hline Median & 58 & 22.5 \\
Mediolateral & 190 & 77.5 \\
Total & 248 & 100 \\
\hline
\end{tabular}

Table 3. Distribution of women giving birth according to the evolution of immediate childbirth.

\begin{tabular}{ccc}
\hline Evolution & Number of cases & Percentage (\%) \\
\hline Simple sequences & 60 & 24.2 \\
Perineal pain & 60 & 24.2 \\
Hematoma & 2 & 0.8 \\
Inflammation of the suture & 9 & 3.6 \\
Pain that interferes with walking & 85 & 39.5 \\
Pain in sitting position & 111 & 44.8 \\
Hemorrhage & 33 & 13.3 \\
\hline
\end{tabular}


Table 4. Distribution of women giving birth according to their experience during episiotomy.

\begin{tabular}{ccc}
\hline Experienced & Frequency & Percentage (\%) \\
\hline Mild pain & 54 & 20.8 \\
Average pain & 40 & 16.7 \\
Severe pain & 76 & 31.7 \\
Undetermined & 77 & 30.8 \\
Total & 248 & 100 \\
\hline
\end{tabular}

Table 5. Distribution of women giving birth according to the evolution on day 9.

\begin{tabular}{ccc}
\hline Evolution & Frequency & Percentage (\%) \\
\hline Simple sequences & 185 & 74.6 \\
Spontaneous pain & 55 & 22.2 \\
Hematoma & 3 & 1.2 \\
\hline
\end{tabular}

Table 6. Distribution of women giving birth according to the relationship between shrinking of the perineum and excision.

\begin{tabular}{cccc}
\hline $\begin{array}{c}\text { Shrinkage of the Perineum } \\
\text { Excision }\end{array}$ & Yes & No & TOTAL \\
\hline Yes & 165 & 64 & 229 \\
No & 5 & 14 & 19 \\
TOTAL & 170 & 78 & 248 \\
\hline
\end{tabular}

$\mathrm{Chi}^{2}=15.8371 \mathrm{p}=0.00007$, Statistically significant association.

\section{complications after 3rd month}

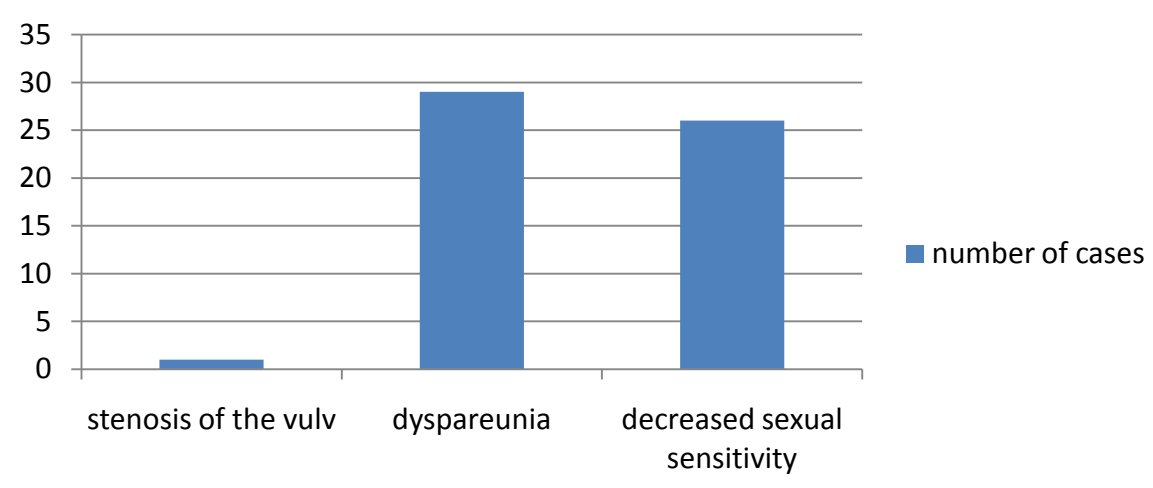

Figure 4. Distribution of women giving birth according to complications found after 3 months.

- Use of absorbable sutures and simple sequences

The relationship between the use of absorbable sutures and simple sequences has been shown in Table 7 .

\section{Discussion}

\section{- Limitations of the study}


Table 7. Distribution of women giving birth according to the relationship between the use of absorbable sutures and simple sequelae.

\begin{tabular}{cccc}
\hline $\begin{array}{c}\text { Simple Frequencies } \\
\text { Resorbable Suture }\end{array}$ & Yes & No & TOTAL \\
\hline Yes & 140 & 56 & 196 \\
No & 45 & 7 & 52 \\
TOTAL & 185 & 63 & 248 \\
\hline
\end{tabular}

$\mathrm{Chi}^{2}=4.95 \mathrm{p}=0.0260$, Statistically significant association.

Interviewing as a collection technique has not always led to objective answers. Also the long-term evolution ( 3 months) could not be evaluated in all the patients, because all did not return to the appointment of the 3rd month. Nevertheless our data are comparable to those of the literature.

\section{- The frequency}

Episiotomy is a common practice in the maternity wards of the health district of Bogodogo. The overall rate during our study during the 04 months was $22 \%$. Episiotomy is common worldwide, but rates vary from country to country. Thus, CHIGBU et al. found a $45 \%$ rate in southeast Nigeria [8]. MORHE et al. in Ghana found a rate of $17.4 \%$ [9]. In KASSAHUN et al. in Ethiopia, it was $40.2 \%$ [10]. In the United States, FRANKMAN et al. found 24.5\% [11]. These large differences in episiotomy practice rates reflect large differences of opinion as to the usefulness of episiotomy. If the usefulness of the episiotomy in certain complicated deliveries is not to be questioned, its place in normal deliveries remains controversial [12]. The prevalence of the practice of excision in countries such as Ethiopia, Nigeria and Burkina Faso, where it is the rule, should also be noted.

\section{- Indications for episiotomy}

In our study, the main indications for episiotomy were vulvoperineal narrowing ( $75 \%$ of cases) and perineal fissure (14.5\% of cases). These indications constitute the direct consequences of excision and nulliparity. KASSAHUN (Ethiopia), CHIGBU (Nigeria) and AMILA (Qatar) reported in their studies that nulliparity was one of the main indications for episiotomy. The other indications cited by these same authors were the long duration of the second phase of labor, young age, instrumental delivery and dystocia presentations [8] [10] [13]. RIETHMULLER et al. in their study reported that nulliparity is a risk factor for the perineum and exposes it to a risk of severe perineal tears; it should not be a systematic indication of episiotomy [14]. For POEN et al., mediolateral episiotomy appeared to significantly protect against these perineal lesions in nulliparous $(\mathrm{OR}=0.54)[15]$. Moreover, for the RIETHMULLER team in potentially dystocic situations (fetal macrosomia, instrumental extraction, breech presentation, occipito-sacral presentation, perineal scarring, twin birth), there is not enough evidence to recommend the practice or not of episiotomy as well as its systematization.

\section{- Prognosis}




\section{As a result of immediate diaper suites}

The evolution was marked by pain, according to most of our patients (3/4). This pain was felt especially when sitting and walking. Several studies have focused on the pain associated with episiotomy. Thus LARSSON et al. showed that the first day of postpartum, after an episiotomy, was marked by a significantly greater frequency of pain and a greater use of analgesics (37\% versus $13 \%, \mathrm{p}<$ 0.001) [16]. Also another study conducted by MC ARTHUR et al. found that pain perceived by patients was greater in the 1st and 7th days after episiotomy than after 1st or 2nd degree tears, or when, the perineum had remained intact [17]. Similarly, in the study by DANNECKER et al. [18], it was found that perineal pains in bed, sitting, walking and defecation were significantly more frequent in the immediate postpartum period in the case of episiotomy. In summary, in the immediate postpartum period, patients with episiotomies would complain of more perineal pain than those with intact perinea's or 1st or 2nd degree tears. Tissue mortification could explain this discomfort.

\section{$\checkmark$ Experience during episiotomy}

She was marked by pain, especially during the repair. This could be explained by the fact that anesthesia was used in only $31.3 \%$ of patients. Pain management should be better respected in all women in labor. Also, at the time of the section, the majority of patients could not distinguish pain from episiotomy from pain from uterine contractions.

\section{$\checkmark$ On Day 9}

Patients reviewed on day 9 had a simple follow-up in the majority of cases $74.60 \%$. Suture release occurred in $16.1 \%$ of cases. CHIGBU [8] in Nigeria found a lower rate of suture release, at $3 \%$. The relatively high rate of suture release in our series could be explained by some of our traditional post-partum practices, namely hot water perineal cleansing; but also, the lack of hygiene (poorly maintained pads) and excessive patient mobilization before day 7. However, when the care given after the layer is well followed, the evolution is generally favorable with a good healing.

\section{$\checkmark$ In the 3rd month}

In our study, of the women who were reviewed, about half $(51.4 \%)$ had resumed sexual intercourse. The main difficulties they encountered were dyspareunia and a decrease in sexual sensitivity. One could explain the low rate of sexual resumption by the fact that in our West African societies, after childbirth, many women move in with their mother-in-law or join their paternal family for a few months. Also, dyspareunia could be explained by poor scarring or psychological trauma caused by pain during childbirth. The difficulties encountered during the resumption of sexual relations have also been reported by several authors. Thus LARSSON et al. [16] at the $8-12$ week postpartum visit reported dyspareunia in $16 \%$ of patients who had an episiotomy versus $11 \%$ in those who had only a spontaneous tear $(\mathrm{p}<0.05)$. However, $30 \%$ of the patients had not yet resumed sexual intercourse. Similarly, the study by SARTORE et al. [19] showed 
that 3 months after delivery the group with episiotomy had more dyspareunia than the group with intact perineum or with 1st or 2nd degree tears. In addition, READING et al. [20] analysed changes in sexuality through a questionnaire sent 3 months after delivery. Concerning the desire to have sexual intercourse, the pleasure obtained and the quality of the relationship, $15 \%$ to $24 \%$ of the patients considered that a change had occurred and attributed it in half of the cases to episiotomy. In the end, one could say that episiotomy seems to generate more dyspareunia during the first weeks of postpartum.

\section{Conclusion}

The WHO recommends for the clinical practice of episiotomy a rate of less than $20 \%$. The episiotomy rate in our study was $22 \%$. A program of continuous improvement of the quality of care concerning episiotomy encompassing various actions (audits, training) could reduce the use of episiotomies. A study in the general population would be needed to confirm our data.

\section{Conflicts of Interest}

The authors declare no conflicts of interest regarding the publication of this paper.

\section{References}

[1] Riteau, A.S. (2004) Female Perineum from Surface to Depth. Thesis for the Certificate of Anatomy, Imaging and Morphogenesis, 2002-2003, University of Nantes, Nantes.

[2] Lansac, J., Body, G., Penotin, F. and Marret, H. (2001) Birth Practice. 3rd Edition, 410.

[3] Vendittelli, F. and Gallot, D. (2006) What Are the Epidemiological Data Concerning Episiotomy? Journal de Gynécologie Obstétrique et Biologie de la Reproduction, 35, 1S12-1S23.

[4] Thacker, S.B. and Banta, H.D. (1983) Benefits and Risks of Episiotomy: An Interpretative Review of the English Language Literature, 1860-1980. Obstetrical \& Gynecological Survey, 38, 322-338.

[5] Sleep, J., Grant, A., Garcia, J., et al. (1984) West Berkshire Perineal Management Trial. BMJ, 289, 587-590.

[6] Woolley, R.J. (1995) Benefits and Risks of Episiotomy: A Review of the English Language Literature since 1980. Part I. Obstetrical \& Gynecological Survey, 50, 806-835.

[7] Loreng, N., Nougtara, A. and Garner, P. (1998) Episiotomy in Burkina Faso. Tropical Doctors, 28, 83-85.

[8] Chigbu, B., Onwere, S., Kamanu, C. and Adibe, E. (2008) Factors Influencing the Use of Episiotomy during Vaginal Delivery in South Eastern Nigeria. East African Medical Journal, 85, 240-243.

[9] Morhe, E.S.K., Sengretsi, S. and Danso, K.A. (2004) Episiotomy in Ghana. International Journal of Gynaecology and Obstetrics, 86, 46-47.

[10] Kassahun, K. and Zufan, L. (2006) Magnitude of Episiotomy in a Teaching Hospital 
in Addis Ababa, Ethiopia. Ethiopian Medical Journal, 44, 205-209.

[11] Frankman, E.A., Wang, L., Bunker, C.H., et al. (2009) Episiotomy in the United States: Has Anything Changed? American Journal of Obstetrics and Gynecology, 200, 573.e1-573.e7.

[12] Buekens, P., Bernard, N., Blondel, B., et al. (1987) Episiotomy and Prevention of Complete and Complicated Tears. A Study in 3 European Countries. Journal de Gynécologie Obstétrique et Biologie de la Reproduction, 16, 513-517.

[13] Amila, H. and Hammoud, M.M. (2008) Indications for the Use of Episiotomy in Qatar. International Journal of Gynecology and Obstetrics, 104, 240-248.

[14] Riethmuller, D., Courtois, L. and Maillet, R. (2006) Liberal versus Restrictive Episiotomy Practices: Are There Specific Obstetrical Indications for Episiotomy? Journal de Gynécologie Obstétrique et Biologie de la Reproduction, 35, 1S32-1S39.

[15] Poen, A.C. and Felt-Bersma, R.J. (1997) Third Degree Obstetric Perineal Tears: Risk Factors and the Preventive Role of Mediolateral Episiotomy. British Journal of $O b$ stetrics and Gynaecology, 104, 563-566.

[16] Larsson, P.G., Bergman, B., et al. (1991) Advantage or Disadvantage of Episiotomy Compared with Spontaneous Perineal Laceration. Gynecologic and Obstetric Investigation, 31, 213-216. https://doi.org/10.1159/000293161

[17] Mc Arthur, A.J. and Macarthur, C. (2004) Incidence, Severity and Determinants of Perineal Pain after Vaginal Delivery a Prospective Cohort Study. American Journal of Obstetrics and Gynecology, 191, 1199-2004.

https://doi.org/10.1016/j.ajog.2004.02.064

[18] Dannecker, C., et al. (2004) Episiotomy and Perineal Tears Presumed to Be Imminent: Randomized Controlled Trial. Acta Obstetricia et Gynecologica Scandinavica, 83, 364-368. https://doi.org/10.1111/j.0001-6349.2004.00366.x

[19] Sartore, A., De Seta, F., Maso, G., et al. (2004) The Effect of Mediolateral Episiotomy on Pelvic Gloor Functions after Vaginal Delivery. Obstetrics \& Gynecology, 103, 669-673. https://doi.org/10.1097/01.AOG.0000119223.04441.c9

[20] Reading, A.E., Sledmere, C.M., et al. (1982) How Women View Post Episiotomy Bread. BMD, 284, 243-246. https://doi.org/10.1136/bmj.284.6311.243 